\title{
Non-Pharmacological Management of Pulmonary Thromboembolism
}

\author{
HS Natraj Setty*, Rahul Patil, Raghavendra Murthy P, Shivanand S Patil, Vijayakumar, and CN Manjunath \\ Sri Jayadeva Institute of Cardiovascular Sciences and Research, India
}

Submission: February 18, 2017; Published: September 20, 2017

*Corresponding author: HS Natraj Setty MD, DM, FICC, Assistant Professor of Cardiology, Sri Jayadeva Institute of Cardiovascular Sciences and Research, Bangalore, Karnataka, India, Tel: 9845612322; 080-26580051; Fax: 080-22977261; Email: drnatrajsetty75@gmail.com

Abstract

Acute massive pulmonary embolism is a most common life-threatening complication, Current treatment paradigm in patients with massive pulmonary thromboembolism mandates prompt risk stratification with aggressive therapeutic strategies. With the advent of endovascular technologies, various catheter-based thrombectomy and thrombolytic devices are available to treat patients with massive or submassive pulmonary thromboembolism.

\section{Management}

The objective of interventional treatment in pulmonary embolism is the removal of obstructing thrombi from the main pulmonary arteries to facilitate RV recovery and improve symptoms and survival [1].

The different modes of intervention used in the treatment of pulmonary embolism include:

a. Percutaneous Transcatheter Interventions

b. Surgical Embolectomy

c. Inferior Vena Cava Filter Insertion

d. Pulmonary endarterectomy (PEA)

\section{a. Percutaneous transcatheter interventions}

Percutaneous Transcatheter Interventions are potentially lifesaving in selected patients with massive or submissive PE [2]. They are usually performed when thrombolysis is contraindicated/failed or when emergency surgical thrombectomy is unavailable or contraindicated. Hybrid therapy that includes both is an emerging strategy. For patients without absolute contraindications to thrombolysis, catheter-directed thrombolysis or pharmaco- mechanical thrombolysis are preferred approaches.

The goals of catheter-based therapy include

(1) Rapidly reducing pulmonary artery pressure, RV strain, and pulmonary vascular resistance (PVR)

(2) Increasing systemic perfusion; and

\section{(3) Facilitating RV recovery}

There are 3 general categories of percutaneous intervention for removing pulmonary emboli and decreasing thrombus burden:

(1) Aspiration thrombectomy,

(2) Thrombus fragmentation, and

(3) Rheolytic thrombectomy.

Aspiration thrombectomy uses sustained suction applied to the catheter tip to secure and remove the thrombus. Thrombus fragmentation has been performed with balloon angioplasty [3], or a more advanced Amplatze catheter, which uses an impeller to homogenize the thrombus [4]. Rheolytic thrombectomy catheters (AngioJet catheters), use a high-velocity saline jet to fragment adjacent thrombus by creating a Venturi effect and removing the debris from an evacuation lumen [5]. Ideal thrombectomy catheters for use in the pulmonary circulation must be readily maneuverable, effective in removal of thromboembolic, and safe by virtue of minimizing distal embolization, mechanical hemolysis, or damage to cardiac structures and pulmonary arteries.

In a systematic review of available cohort data comprising a total of 348 patients, clinical success with percutaneous therapy alone for patients with acute massive PE was 8\% (aspiration thrombectomy 81\%; fragmentation 82\%; rheolytic thrombectomy $75 \%$ ) and $95 \%$ when combined with local infusion of thrombolytic agents (aspiration thrombectomy $100 \%$; fragmentation 90\%; rheolytic thrombectomy 91\%) 
[6]. Only operators experienced with these techniques should perform a catheter-based intervention. Invasive arterial access is recommended for patients with shock or hypotension to help guide vasopressor management. Patients with massive PE who have contraindications to fibrinolytic therapy who present to centers unable to offer catheter or surgical embolectomy should be considered for urgent transfer to a center with these services available so that they can be evaluated for this therapy. Jaff, et al. [7] describes the procedure in brief. Through a $6 \mathrm{~F}$ femoral venous sheath, a $6 \mathrm{~F}$ angled pigtail catheter is advanced into each main pulmonary artery, followed by injection of low-osmolar or isosmolar contrast ( $30 \mathrm{~mL}$ over 2 seconds). Either UFH 70IU/ $\mathrm{kg}$ intravenous bolus, with additional heparin as needed to maintain an activated clotting time 250 seconds or the direct thrombin inhibitor bivalirudin $(0.75 \mathrm{mg} / \mathrm{kg}$ intravenous bolus, then $1.75 \mathrm{mg}$ kg $1 \mathrm{~h} 1$ ) should be used for anticoagulation. For rheolytic thrombectomy, a $6 \mathrm{~F}$ multipurpose guiding catheter may be used to reach the thrombus, which is crossed with a 0.014 inch hydrophilic guidewire (Choice PT Extra-Support, Boston Scientific, Natick, MA). Temporary transvenous pacemaker insertion may be required during rheolytic thrombectomy. In general, mechanical thrombectomy should be limited to the main and lobar pulmonary arterial branches. For patients with massive PE, the procedure should continue until systemic hemodynamics stabilize, regardless of the angiographic result. Substantial improvement in pulmonary blood flow may result from what appears to be an only modest angiographic improvement.

Major complications (approx 2\%), may include death from worsening RV failure, distal embolization, pulmonary artery perforation with lung hemorrhage, systemic bleeding complications, pericardial tamponade, heart block or bradycardia, hemolysis, contrast-induced nephropathy, and puncture-related complications [8].

\section{b. Surgical embolectomy}

The first successful surgical pulmonary embolectomy was performed in 1924. Emergency surgical embolectomy with cardiopulmonary bypass has re-emerged as an effective strategy for managing patients with massive PE or submissive PE with RV dysfunction when contraindications preclude thrombolysis [9]. This operation is also suited for acute PE patients who require surgical excision of a right atrial thrombus or paradoxical embolism. Surgical embolectomy can also rescue patients whose condition is refractory to thrombolysis [10]. The results of embolectomy will be optimized if patients are referred before the onset of cardiogenic shock.

Older case series suggest a mortality rate between $20 \%$ and $30 \%$ despite surgical embolectomy [11], Following median sternotomy, normothermic cardiopulmonary bypass should be instituted. Aortic cross-clamping and cardioplegic cardiac arrest should be avoided [12]. With bilateral PA incisions, clots can be removed from both pulmonary arteries down to the segmental level under direct vision. Prolonged periods of post-operative cardiopulmonary bypass and weaning may be necessary for the recovery of RV function. Preoperative thrombolysis increases the risk of bleeding, but it is not an absolute contraindication to surgical embolectomy [13].

Recommendations for Catheter/ Surgical Embolectomy and Fragmentation

a. Depending on local expertise, either catheter embolectomy and fragmentation or surgical embolectomy is reasonable for patients with massive $\mathrm{PE}$ and contraindications to fibrinolysis (Class IIa; Level of Evidence C).

b. Catheter embolectomy and fragmentation or surgical embolectomy are reasonable for patients with massive PE who remain unstable after receiving fibrinolysis (Class IIa; Level of Evidence C).

c. For patients with massive PE who cannot receive fibrinolysis or who remain unstable after fibrinolysis, it is reasonable to consider a transfer to an institution experienced in either catheter embolectomy or surgical embolectomy if these procedures are not available locally and safe transfer can be achieved (Class IIa; Level of Evidence C).

d. Either catheter embolectomy or surgical embolectomy may be considered for patients with submassive acute PE judged to have clinical evidence of adverse prognosis (new hemodynamic instability, worsening respiratory failure, severe RV dysfunction, or major myocardial necrosis) (Class IIb; Level of Evidence C).

e. Catheter embolectomy and surgical thrombectomy are not recommended for patients with low-risk PE or submassive acute PE with minor RV dysfunction, minor myocardial necrosis, and no clinical worsening (Class III; Level of Evidence C).

\section{c. Inferior vena cava filter insertion}

The ICOPER (International Cooperative Pulmonary Embolism Registry) registry examined clinical outcomes in patients treated with IVC filters for PE [14] The PREPIC Trial (Prevention du Risque d'Embolie Pulmonaire par Interruption Cave) [15] randomized 400 patients with proximal deep venous thrombosis (DVT) at high risk for PE.

Observational studies suggest that insertion of a venous filter might reduce PE-related mortality rates in the acute phase, $[16,17]$ benefit possibly coming at the cost of an increased risk of recurrence of VTE [17]. Complications associated with permanent IVC filters are common, although they are rarely fatal [18]. Overall, early complications which include insertion site thrombosis occur in approximately $10 \%$ of patients. Placement 
of a filter in the superior vena cava carries the risk of pericardial tamponade [19]. Late complications are more frequent and include recurrent DVT in approximately $20 \%$ of patients and post-thrombotic syndrome in up to $40 \%$.Occlusion of the IVC affects approximately $22 \%$ of patients at 5 years and $33 \%$ at 9 years, regardless of the use and duration of anticoagulation $[20,21]$. Eight-year follow-up of a randomized study on 400 patients with DVT (with or without PE), all of whom had initially received anticoagulant treatment for at least 3 months, showed that patients undergoing permanent IVC filter insertion had a reduced risk of recurrent $\mathrm{PE}$ at the cost of an increased risk of recurrent DVT and no overall effect on survival [20].

Non-permanent IVC filters are classified as temporary or retrievable devices. Temporary filters must be removed within few days, while retrievable filters can be left in place for longer periods [22]. When non-permanent filters are used, it is recommended that they are removed as soon as it is safe to use anticoagulants. Despite this, they are often left in situ for longer periods, with a late complication rate of at least $10 \%$; this includes filter migration, tilting or deformation, penetration of the cava wall by filter limbs, fracturing of the filter and embolization of fragments, and thrombosis of the device $[23,24]$.

Recommendations on IVC Filters in the Setting of Acute PE

a. Adult patients with any confirmed acute PE (or proximal DVT) with contraindications to anticoagulation or with active bleeding complication should receive an IVC filter (Class I; Level of Evidence B).

b. Anticoagulation should be resumed in patients with an IVC filter once contraindications to anticoagulation or active bleeding complications have resolved (Class I; Level of Evidence B).

c. Patients who receive retrievable IVC filters should be evaluated periodically for filter retrieval within the specific filter's retrieval window (Class I; Level of Evidence C).

d. For patients with recurrent acute PE despite therapeutic anticoagulation, it is reasonable to place an IVC filter (Class IIa; Level of Evidence C).

e. For DVT or PE patients who will require permanent IVC filtration (eg, those with a long-term contraindication to anticoagulation), it is reasonable to select a permanent IVC filter device (Class IIa; Level of Evidence C).

f. For DVT or PE patients with a time-limited indication for an IVC filter (eg, those with a short-term contraindication to anticoagulation therapy), it is reasonable to select a retrievable IVC filter device (Class IIa; Level of Evidence C).

g. Placement of an IVC filter may be considered for patients with acute PE and very poor cardiopulmonary reserve, including those with massive PE (Class IIb; Level of Evidence C). h. An IVC filter should not be used routinely as an adjuvant to anticoagulation and systemic fibrinolysis in the treatment of acute PE (Class III; Level of Evidence C).

\section{d. Pulmonary endarterectomy (PEA)}

PEA is the treatment of choice for CTEPH. In Europe, inhospital mortality is currently as low as $4.7 \%$ in expert centers [25]. The majority of patients experience substantial relief from symptoms and near-normalization of hemodynamics [26-28]. In contrast to surgical embolectomy for acute PE, treatment of CTEPH necessitates a true endarterectomy through the medial layer of the pulmonary arteries, which is performed under deep hypothermia and circulatory arrest [29]. General operability criteria include preoperative New York Heart Association functional class II-IV and the surgical accessibility of thrombi in the main, lobar, or segmental pulmonary arteries. Advanced age per se is no contraindication for surgery. There is no pulmonary vascular resistance threshold or measure of RV dysfunction that absolutely precludes PEA [30]. Patients who do not undergo surgery, or suffer from persistent or residual pulmonary hypertension after PEA, face a poor prognosis. Advances in balloon pulmonary angioplasty are continuing in an attempt to make this technique a therapeutic alternative for selected patients with non-operable CTEPH [31,32].

\section{Conclusion}

Rapid risk stratification by identifying patients with acute massive and acute submassive PE is essential in determining appropriate management. Acute PE can be associated with high rates of mortality. Devices for catheter-directed thromboembolectomy continue to emerge and main stay in the management of pulmonary thrombo embolism. The use of modern Catheter-directed therapy (CDT) has proven to be a lifesaving treatment in patients dying from acute massive PE.

\section{References}

1. Engelberger RP, Kucher N (2011) Catheter-based reperfusion treatment of pulmonary embolism. Circulation 124(19): 2139-2144.

2. Kucher N (2007) Catheter embolectomy for acute pulmonary embolism. Chest 132: 657-663.

3. Handa K, Sasaki Y, Kiyonaga A, Fujino M, Hiroki T, et al. (1988) Acute pulmonary thromboembolism treated successfully by balloon angioplasty: a case report. Angiology 39(8): 775-778.

4. Fava M, Loyola S (2003) Applications of percutaneous mechanical thrombectomy in pulmonary embolism. Tech Vasc Interv Radiol 6(1): 53-58.

5. Cho KJ, Dasika NL (2000) Catheter technique for pulmonary embolectomy or thrombofragmentation. Semin Vasc Surg 13: 221-235.

6. Skaf E, Beemath A, Siddiqui T, Janjua M, Patel NR, et al. (2007) Cathetertip embolectomy in the management of acute massive pulmonary embolism. Am J Cardiol 99(3): 415-420.

7. Jaff MR, McMurtry MS, Archer SL, Cushman M, Goldenberg N, et al. (2011) Management of Massive and Submassive Pulmonary Embolism, Iliofemoral Deep Vein Thrombosis, and Chronic Thromboembolic Pulmonary Hypertension: A Scientific Statement From the American Heart Association. Circulation 123(16): 1788 -1830. 
8. Engelberger RP, Kucher N (2011) Catheter-based reperfusion treatment of pulmonary embolism. Circulation 124(19): 2139-2144.

9. Sukhija R, Aronow WS, Lee J, Kakar P, McClung JA, et al. (2005) Association of right ventricular dysfunction with in-hospital mortality in patients with acute pulmonary embolism and reduction in mortality in patients with right ventricular dysfunction by pulmonary embolectomy. Am J Cardiol 95(5): 695-696.

10. Meneveau N, Se'ronde MF, Blonde MC, Legalery P, Didier-Petit K, et al. (2006) Management of unsuccessful thrombolysis in acute massive pulmonary embolism. Chest 129(4): 1043-1050.

11. Stein PD, Alnas M, Beemath A, Patel NR (2007) Outcome of pulmonary embolectomy. Am J Cardiol 99(3): 421-423.

12. Leacche M, Unic D, Goldhaber SZ, Rawn JD, Aranki SF, et al. (2005) Modern surgical treatment of massive pulmonary embolism: results in 47 consecutive patients after rapid diagnosis and aggressive surgical approach. J Thorac Cardiovasc Surg 129(5): 1018-1023.

13. Aklog L, Williams CS, Byrne JG, Goldhaber SZ (2002) Acute pulmonary embolectomy: a contemporary approach. Circulation 105(12): 14161419.

14. Goldhaber SZ, Visani L, De Rosa M (1999) Acute pulmonary embolism: clinical outcomes in the International Cooperative Pulmonary Embolism Registry (ICOPER). Lancet 353(9162): 1386-1389.

15. Decousus H, Leizorovicz A, Parent F, Page Y, Tardy B, et al. (1998) A clinical trial of vena caval filters in the prevention of pulmonary embolism in patients with proximal deep-vein thrombosis: Pre'vention du Risque d'Embolie Pulmonaire par Interruption Cave Study Group. N Engl J Med 338(7): 409-415.

16. Stein PD, Matta F, Keyes DC, Willyerd GL (2012) Impact of vena cava filters on in-hospital case fatality rate from pulmonary embolism. Am J Med 125(5): 478-484.

17. Muriel A, Jimenez D, Aujesky D, Bertoletti L, Decousus H, et al. (2014) Survival effects of inferior vena cava filter in patients with acute symptomatic venous thromboembolism and a significant bleeding risk. J Am Coll Cardiol 63(16): 1675-1683.

18. Hann CL, Streiff MB (2015) The role of vena caval filters in the management of venous thromboembolism. Blood Rev 19(4): 179-202.

19. Kucher N (2011) Clinical practice. Deep-vein thrombosis of the upper extremities. N Engl J Med 364(9): 861-869.

20. PREPIC Study Group (2005) Eight-year follow-up of patients with permanent vena cava filters in the prevention of pulmonary embolism: the PREPIC (Prevention du Risque d'Embolie Pulmonaire par Interruption Cave) randomized study. Circulation 112(3): 416-422.
21. Failla PJ, Reed KD, Summer WR, Karam GH (2005) Inferior vena caval filters: key considerations. Am J Med Sci 330(2): 82-87.

22. Kaufman JA, Rundback JH, Kee ST, Geerts W, Gillespie D, et al. (2009) Development of a research agenda for inferior vena cava filters: proceedings from a multidisciplinary research consensus panel. J Vasc Interv Radiol 20(6): 697-707.

23. Zhu X, Tam MD, Bartholomew J, Newman JS, Sands MJ, et al. (2011) Retrievability and device-related complications of the G2 filter: a retrospective study of 139 filter retrievals. J Vasc Interv Radiol 22(6): 806-812.

24. Karmy-Jones R, Jurkovich GJ, Velmahos GC, Burdick T, Spaniolas K, et al. (2007) Todd Practice patterns and outcomes of retrievable vena cava filters in trauma patients: an AAST multicenter study. J Trauma 62(1): $17-24$.

25. Rubens FD, Bourke M, Hynes M, Nicholson D, Kotrec M, et al. (2007) Surgery for chronic thromboembolic pulmonary hypertension: inclusive experience from a national referral center. Ann Thorac Surg 83(3): 1075-1081.

26. Ogino H, Ando M, Matsuda H, Minatoya K, Sasaki H, etal. (2006) Japanese single-center experience of surgery for chronic thromboembolic pulmonary hypertension. Ann Thorac Surg 82(2): 630-636.

27. Rubens FD, Bourke M, Hynes M, Nicholson D, Kotrec M, et al. (2007) Surgery for chronic thromboembolic pulmonary hypertension: inclusive experience from a national referral center. Ann Thorac Surg 83: $1075-1081$

28. Bonderman D, Skoro-Sajer N, Jakowitsch J, Adlbrecht C, Dunkler D, et al (2007) Predictors of outcome in chronic thromboembolic pulmonary hypertension. Circulation 115(16): 2153-2158.

29. Yoshimi S, Tanabe N, Masuda M, Sakao S, Uruma T, et al. (2008) Survival and quality of life for patients with peripheral type chronic thromboembolic pulmonary hypertension. Circ J 72(6): 958-965.

30. Suntharalingam J, Goldsmith K, Toshner M, Doughty N, Sheares KK, et al. (2007) Role of NT-proBNP and 6MWD in chronic thromboembolic pulmonary hypertension. Respir Med 101: 2254-2262.

31. Thomson B, Tsui SS, Dunning J, Goodwin A, Vuylsteke A, et al. (2008) Pulmonary endarterectomy is possible and effective without the use of complete circulatory arrest: the UK experience in over 150 patients. Eur J Cardiothorac Surg 33(2): 157-163.

32. Hoeper MM, Barbera JA, Channick RN, Hassoun PM, Lang IM, et al. (2009) Diagnosis, assessment, and treatment of non-pulmonary arterial hypertension pulmonary hypertension. J Am Coll Cardiol 54(suppl): S85-S96.
Your next submission with Juniper Publishers will reach you the below assets

- Quality Editorial service

- Swift Peer Review

- Reprints availability

- E-prints Service

- Manuscript Podcast for convenient understanding

- Global attainment for your research

- Manuscript accessibility in different formats

( Pdf, E-pub, Full Text, Audio)

- Unceasing customer service

Track the below URL for one-step submission https://juniperpublishers.com/online-submission.php 